\title{
Proof of Ethics with Math
}

\author{
Kiumars Hashemi Fard \\ South Pars Gas Complex, Phase 12 , Petro Pars \\ *Corresponding Author E-mail: kiumars.hf@gmail.com
}

Received: 19 June 2019, Revised: 16 September 2019, Accepted: 2 December 2019

\begin{abstract}
In this paper, we examine the relation between ethics and mathematics and, through the formulas, we conclude a negative or positive behavior. If it was negative, it would behave incorrectly and if it was positive, it would be correct. Of course, each behavior is considered completely separate, and many of the benefits to each behavior may not be known yet. So any behavior will have either positive or negative effects; here is just one example of this template to illustrate them. Smoking was considered as a behavior. Given the advantages and disadvantages, an impact was defined for each, and eventually these impacts were expressed in terms of numbers, and the result was a negative number, which indicates that smoking is a negative behavior.
\end{abstract}

Keywords: Ethics, Mathematics, Proof.

\section{Introduction}

\section{What is Math?}

Mathematics is the study of quantities and structures, and space and transformation (change). Another view of mathematics is knowledge, in which we arrive at precise and new results with logical reasoning of the principles and definitions (other views have been expressed in the philosophy of mathematics). Although mathematics is not a natural science, the particular structures that mathematicians are researching about are more of natural science, especially physics, and they extend in a space separate from nature and purely, so that the natural sciences return to math to solve their problems to answer and compare with it. Natural science, engineering, economics, and medicine rely heavily on mathematics, but mathematicians sometimes mathematical (and not applied) methods to define some structures (wikipedia, 2019).

\section{Math History}

Ancient Egyptians used calculus and geometry more than 5,000 years ago to measure and map the land and build pyramids at very high precision. The Sumerians discovered the fundamental ideas of mathematics about 3800 years ago. The ancient plate of Babylonian civilization also shows signs of computation that compares the length of each side of the triangle with its chord. This plate shows that the Babylonians had discovered the famous relationship with Pythagoras about a thousand years ago (wikipedia, 2019).

The science of calculus deals with numbers and calculations. On this account, 
the four main actions are: addition, subtraction, multiplication and division. The geometry of science is the study of lines, angles, shapes, and volumes. Greeks such as Euclid, about 2500 years ago, set most of the basic laws of geometry (theorems of geometry). Algebra is a kind of mathematical summary that uses signs such as $\mathrm{x}$ and $\mathrm{y}$ to represent unknown quantities. This science was also developed by Iranian scholars, like Khwarazmi, about 1200 years ago. Calculus, geometry, and algebra are the foundations of mathematics.

Mathematics is a kind of scientific language. Engineers, physicists, and other scientists all use mathematics in their work. Other experts who are interested in studying numbers, quantities, shapes, and space are purely interested in pure mathematics (inappropriate). The number theory, which includes the study of the right numbers and the way in which they operate, is a branch of pure mathematics. In the new world, mathematics is one of the key elements of electronics and computer science.

\section{What is Ethics?}

The science of ethics is a branch of the human sciences, whose subject matter is the identification of the values and the ways in which virtues are acquired and the abandonment of bad ethics. In philosophy of ethics, there are different perspectives on good or bad. For example, in one view, it is only good if it has the desired result (s) (outcome/ending), but another view, without rejecting the desired result, is inherent in the goodness of a thing (Task force). The issue of ethics, due to its scientific and practical status in religious studies, has always been a matter for the scholars of religion. Also, every school has a moral discourse, because morality is rooted in human nature and everyone loves it. Some religions accept and claim the second tendency in morality. In religious ethics, these outcomes may also occur in another universe that is materialistic, but in nonreligious ethics, the eventual outcome of a human society, for example, is considered only in the material world. In this ethics, the micro-patterns of morality and what are the desired results for human society can be determined by the consensus of prominent psychologists and sociologists, not necessarily the custodians of religion.

According to relation ethics with other sciences. The position of morality in the map of science is at the end.

The classification of science by Khajeh Naseer al-Din Tusi at the beginning of Naseri's book of ethics has brought ethical science among other sciences:

1. Theory: Their subject matter is dependent on the willful movement of man.

a. Our Latitude: The subject is single from the material

b. Math

c. Natural

2. Practice: The existence of their subject matter is independent of the voluntary movement of man. These knowledge sciences are the components of voluntary movements and humanistic works of the human being, in such a way as to organize their lives and bring them to their proper perfection, Khoja Nasir Tusi (1979).

Also, Le Petit Robert's culture is as follows, Ethics Good and Bad Science, Principles of Behavior, Theory of Human Being as Goals for Good. Ethics, a set of different forms of a person's mood is defined as behavior. Morality often depends on an ideal tradition (the Kantian model) that distinguishes between what is and what it should be, while customs are related to a materialistic tradition (the Spinoza model), which only seeks to advance existing realities.

Universal happiness is achieved through logical behavior, Spinoza (1997). From the point of view of déontologie, ethics is discussed in relation to the system of 
assignments that must be pursued in a profession.

From the point of view of the general and technical language of morality to three. The meaning is the meaning of instinct, Nature, Habit, and the sum of that ethics.

Moral trait: the act of doing a moral act in certain circumstances, subjectively and conditionally, such as generosity and the lying of the moral act: the type of act that one can judge whether it's good or bad. It can be conscious or unconscious and habitual (in the form of a creation). Like giving a lib and giving it a lie.

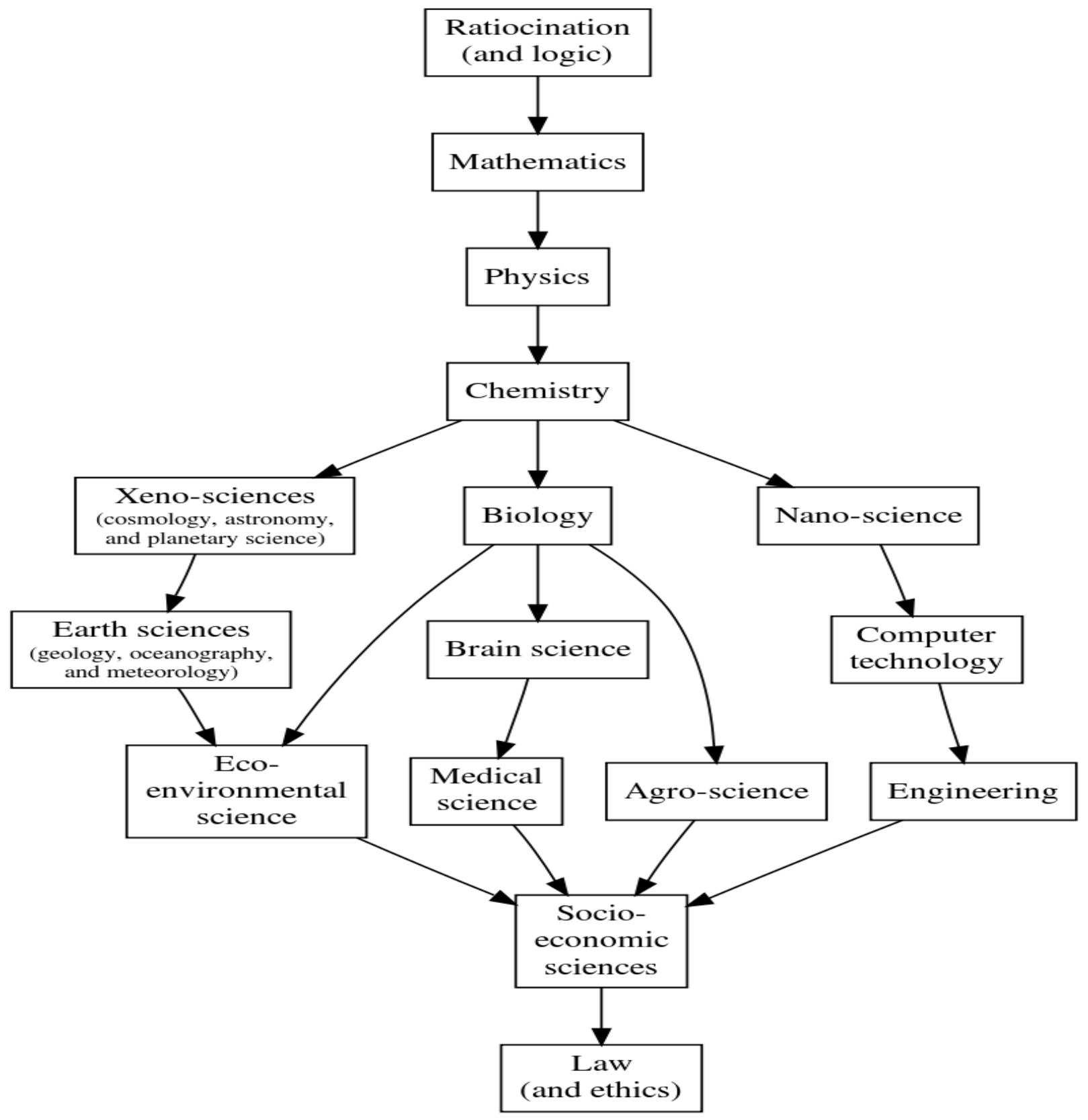

Figure 1.

Results and Discussion 
The science of computing it is called the mother of all sciences. Ethics is a set of behaviors. It has been tried to prove ethics through mathematics. In that way, an interval is defined for each separate behavior. Disadvantages and benefits are combined and at the end of the number obtained if it is positive, it is the correct behavior and if it is negative, then it is doing the wrong behavior. In this way, each mood or behavior is examined separately. The value $x_{i}$ is defined as behavioral deficits and $\mathrm{y}_{\mathrm{i}}$ is defined as good behavior.

$$
\begin{aligned}
& -\infty<\mathrm{x}_{\mathrm{i}}<0 \\
& 0<\mathrm{y}_{\mathrm{i}}<+\infty
\end{aligned}
$$

Which will be explained below. $+\infty$, because a behavior can have a positive effect for later generations, and a behavior can have a negative effect for later generations, so $-\infty$ is considered. Each behavior has disadvantages and advantages. Disadvantages also negatively affect the negative effects of the individual, society, and so on, and ultimately all the negative numbers of the disadvantages of a behavior are aggregated. We make the same calculations for the benefits of the same behavior, that is, every kind of behavior has advantages that effects on themselves, society, etc., the positive numbers are summed up.

Finally, all the numbers obtained from the disadvantages and benefits are combined, if the number is positive, then that behavior is correct and otherwise incorrect. As stated, this method should be investigated for each individual behavior. Here we will examine a behavior with this method. We would like to demonstrate in mathematical language that smoking is positive or negative.

Table 1. Benefits, harms, impact

\begin{tabular}{cccc}
\hline $\begin{array}{c}\text { Effect level } \\
-\infty<\mathbf{x i}<\mathbf{0}\end{array}$ & (xi) Disadvantages & $\begin{array}{c}\text { Effect level } \\
\mathbf{0}<\mathbf{y}_{\mathbf{i}}<+\infty\end{array}$ & $\begin{array}{c}\left(\mathbf{y}_{\mathbf{i}}\right) \\
\text { Advantages }\end{array}$ \\
\hline-1 & $\mathrm{X}_{1}=$ Loss of hair & +1 & $\mathrm{Y}_{1}=$ Psychological evacuation \\
-1 & $\mathrm{X}_{2}=$ Cataract & - & - \\
-1 & $\mathrm{X}_{3}=$ wrinkle & - & - \\
-1 & $\mathrm{X}_{4}=$ Hearing loss & - & - \\
-1 & $\mathrm{X}_{5}=$ Skin Cancer & - & - \\
-1 & $\mathrm{X}_{6}=$ Corrosion of teeth & - & - \\
-1 & $\mathrm{X}_{7}=$ Osteoporosis & - & - \\
-1 & $\mathrm{X}_{8}=$ Heart disease & - & - \\
-1 & $\mathrm{X}_{9}=$ Ulcers & - & - \\
-1 & $\mathrm{X}_{10}=$ Change the color of the fingers & - & - \\
-1 & $\mathrm{X}_{11}=$ Cancer of the womb and & - & - \\
-1 & $\mathrm{X}_{12}=$ Deformation of sex cells in men & - & - \\
-1 & $\mathrm{X}_{13}=$ Cancer & - & - \\
\hline
\end{tabular}

It is worth noting that, in this method, a table is made that has four columns; the first column indicates the benefits of smoking; in the second column, the effect of the benefit is $0<$ yi $<+\infty$; the third column consists of the disadvantages of smoking; in the fourth column, the effect of each of the disadvantages is written down to $-\infty<x i<0$. Finally, using the following equation, it is 
obtained from a positive or negative integer (Leathhald, 2014).

$$
\sum_{i>-\infty}^{n} x \mathrm{i}+\sum_{i<+\infty}^{n} y i>0 \text { or }<0
$$

Also, for larger and smaller values, no equal is taken into account because no behavior is absolutely positive or absolutely negative.

It is worth noting that every benefit or disadvantage has a different effect, here the magnitude of each of the effects is considered to be 1 to the loss and is considered for the benefit of any benefit of +1 . Expressing the exact extent of the effect of benefit or harm is beyond the scope of this article and requires extensive research for any behavior.

According Table 1 and Equation 1 we have Equation 2:

$\sum_{i>-\infty}^{n} x i+\sum_{i<+\infty}^{n} y i=13 \times(-1)+(+1)=-12<0$

It can be seen that the resulting number is 12 , which is a negative number, so this behavior has more negative effects than its positive effects, so doing is irrational.

According to the results, smoking is a negative behavior from a mathematical point of view.

\section{Acknowledgements}

The author thanks Dr. Hussein Elahi Qamshei and Mrs. Zahra Mehrabi.

\section{Reference}

Brouwer, L. (n.d.). What Is Mathematics, Retrieved July 17, 2019. Fromhttps://fa.wikipedia.org/2019/2/4/wi ki/ Mathematics.

Brouwer, L. (n.d.). What Is Ethics, Retrieved July 17 , 2019Fromhttps://fa.wikipedia.org/2019/2/ 4wiki/ Ethics.

Khajeh, NT. (1979). Akhlagh Naseri, Tehran: Zar.

Leathhald, L. (1981). Mathematics, Tehran: Nashr Daneshgahi.

Spinoza, B. (1997). Ethics , Tehran: Nashr Daneshgahi.

How to cite this article: Kiumars Hashemi Fard, Proof of Ethics with Math. International Journal of Advanced Studies in Humanities and Social Science, 2020, 9(1), 84-88. http://www.ijashss.com/article 105643.html 